\title{
A UNIVERSIDADE PÚBLICA PARA OS JOVENS DAS CLASSES POPULARES: NARRATIVAS DE SUPERAÇÃO E A LUTA POR TRANSFORMAÇÃO SOCIAL
}

\author{
Francisca Denise Silva Vasconcelos iD1, Luana Paiva da Silva (iD), Roniel Sousa \\ Damasceno iD 3 Bárbara Ellen Viana Sales iD 4
}

Resumo: As políticas de ações afirmativas vêm aumentando o acesso ao ensino superior para jovens oriundos de classes populares. Desse modo, o objetivo do presente artigo é discutir os significados da universidade pública para esses jovens. Para isso, apresentaremos os dados obtidos por meio da realização de entrevistas semiestruturadas com 27 estudantes da Universidade Federal do Ceará - Campus Sobral. Para a análise dos dados utilizamos como ferramenta o software IRAMUTEQ e o suporte teórico da Análise de Discurso trazida por Orlandi. Os relatos dos estudantes permitem compreender que a entrada deles na Universidade Pública está vinculada à negação das instituições privadas de ensino superior, que trazem em seu bojo impossibilidades a esses sujeitos, bem como à superação de contextos de empobrecimento através da possibilidade de emancipação e concretização de seus projetos de vida. Com isso, notamos a construção de trajetórias de superação pautadas na luta por reconhecimento e transformação social.

Palavras-chave: Ensino Superior; Universidade Pública; Classes Populares; Juventude.

\section{THE PUBLIC UNIVERSITY FOR YOUNG PEOPLE OF THE POPULAR CLASSES: NARRATIVES OF OVERCOMING AND THE STRUGGLE FOR SOCIAL TRANSFORMATION}

\begin{abstract}
Affirmative action policies have been increasing access to higher education for young people from the lower classes. Thus, the aim of this article is to discuss the meanings of the public university for these young people. For this purpose, we will show the data obtained by conducting partially structured interviews with 27 students from the Federal University of Ceará - Sobral Campus. For data analysis, we used the IRAMUTEQ software and the theoretical support of Discourse Analysis given by Orlandi as a tool. The students' reports allow us to understand that their admission to the public university is linked to the rejection of private higher education institutions, that bring impossibilities to these individuals, as well as overcoming impoverished situations through the

\footnotetext{
${ }^{1}$ Doutora em Sociologia pela Universidade Federal do Ceará (UFC). Professora efetiva na Universidade Federal do Ceará (UFC), Câmpus de Sobral. E-mail: denisevasconcelos@ufc.br. ${ }^{2}$ Graduanda em Psicologia pela Universidade Federal do Ceará (UFC), Campus de Sobral. E-mail: Ilppaiva09@gmail.com.

${ }^{3}$ Graduando em Psicologia pela Universidade Federal do Ceará (UFC), Campus de Sobral. E-mail: ronielsousa1@gmail.com.

${ }^{4}$ Graduanda em Psicologia pela Universidade Federal do Ceará (UFC), Campus de Sobral. E-mail: bellen018@gmail.com.
} 
possibility of emancipation and realization of their life projects. In this way, we note the construction of overcoming trajectories related to the struggle for recognition and social transformation.

Keywords: Higher Education; Public University; Popular Classes; Youth.

\section{Introdução}

Ao longo de todo o processo histórico de constituição e desenvolvimento das universidades brasileiras nos deparamos com um espaço que, durante muito tempo, foi reservado àqueles que possuíam poder sobre os aspectos econômicos e culturais do país (ZAGO; PAIXÃO; PEREIRA, 2016). A universidade, desde sua criação, foi um meio pelo qual jovens de classes média e alta puderam legitimar sua distinção das demais classes, tendo acesso a formações acadêmicas e ao conhecimento científico, que permaneceram restritos às classes populares ${ }^{5}$ durante muitos anos. Dessa forma, as universidades tornaram-se espaços de legitimação das desigualdades entre classes, o que podemos observar ainda atualmente (NIEROTKA; TREVISOL, 2016).

Entretanto, podemos perceber nos últimos anos uma crescente mudança neste cenário. O acesso ao ensino superior para jovens pobres, tanto em universidades públicas quanto privadas, que antes era improvável, tem se mostrado como uma possibilidade, em especial a partir de políticas voltadas para a viabilização da entrada destes jovens na universidade. Podemos citar programas como o REUNI (Programa de Apoio a Planos de Reestruturação e Expansão das Universidades Federais), o FIES (Fundo de Financiamento ao Estudante do Ensino Superior), PROUNI (Programa Universidade Para Todos) e a Política de Cotas - criada a partir da lei 12.711/2012 - , que se apresentaram como importantes fatores na legitimação dos direitos e possibilidades de jovens das classes populares em ingressar no ensino superior (CORBUCCI et al., 2009; PAULA, 2011; NIEROTKA; TREVISOL, 2016; SCHWARTZMAN, 2018; ZAGO; PAIXÃO; PEREIRA, 2016).

Dessa forma, vemos que a história das universidades tem em si um considerável processo, pelo qual podemos começar a compreender a importância de pensarmos formas de democratização do acesso ao ensino superior. Assim, para nos aprofundarmos sobre essas possibilidades, pensa-se na importância de abrir um campo de análise que permita o conhecimento do impacto dessa tentativa de democratização sobre jovens pobres, podendo analisar as motivações que os fazem optar pela universidade, os contextos

\footnotetext{
${ }^{5} \mathrm{Na}$ literatura utilizada para a discussão deste artigo, deparamo-nos com uma diversidade de categorias que dão conta do contingente de indivíduos que advêm de contextos de pobreza (empobrecidos) e marginalização, a saber: classes populares, massas populares, meios populares, camadas populares. Desta forma, optamos por classes populares como categoria analítica que representa os sujeitos que têm como única opção em seus percursos de escolarização, as instituições públicas de Educação - a totalidade de nossos informantes de pesquisa, em suas narrativas, apresentou alguma passagem nas escolas públicas, em suas trajetórias de escolarização; e uma parcela significativa teve toda a trajetória nessas instituições (EVANGELISTA; MACIEL, 2019; FREIRE, 2005; LAHIRE, 1997; PATTO, 1999, 2015; PIOTTO, 2009, 2010; RÊGO; BENEVIDES, 2019; SILVA; LEME, 2019; SOUZA, 2009; ZAGO, 2006$).$
} 
sociais nos quais estão inseridos e as significações apresentadas a partir da mudança desses contextos.

Nesse sentido, pensando sobre este espaço de investigação acerca da das narrativas construídas por estes jovens pobres sobre o acesso do Ensino Superior que nos permitimos realizar o presente estudo. Este artigo contém parte dos resultados da pesquisa intitulada "Não à 'Vida Maria': Contextos de superação e a inserção de jovens pobres na Universidade Pública", vinculada ao Laboratório de Estudos das Desigualdades \& Diversidades (LAEDDES) do curso de Psicologia da Universidade Federal do Ceará (UFC) - Campus Sobral. Essa pesquisa foi realizada durante o período de junho de 2018 a dezembro de 2019, com estudantes da referida universidade e suas respectivas mães, ou mesmo pessoas que consideram exercer essa função.

Nosso estudo mais amplo teve como objetivo estudar o contexto que configura histórias de vida de jovens oriundos de classes populares que entraram no ensino superior e que são filhos ou filhas de mulheres provedoras. A presente discussão nos ajuda a compreender a pertinência do tema sobre a entrada de jovens pobres no ensino superior público, visto que, durante muito tempo, essa classe possuiu seus direitos denegados e sua presença em instituições de ensino superior, sejam elas públicas ou privadas, foi vista como ameaça aos poderes da classe dominante. Entendemos também a importância de considerar as mães provedoras como uma das possíveis variáveis de mudança desses contextos, pois compreendemos a mulher como sujeito que historicamente foi cobrado e rebaixado, tendo que assumir a liderança de suas famílias em vista de muitas ausências (PRIORE; PINSKY, 2012). Assim, percebemos as mães como figuras de enfrentamento ao ciclo socialmente construído de empobrecimento e que transmitem seus valores para seus filhos.

Dessa forma, a partir da pesquisa realizada, buscamos entender quais as condições que favoreceram a inserção desses estudantes na universidade pública, bem como os significados produzidos a partir do seu ingresso. Entretanto, para fins deste estudo, nos debruçaremos apenas sobre os discursos dos estudantes entrevistados, tendo como ferramentas o software IRAMUTEQ para o processamento dos dados coletados e de uma análise pautada na análise do discurso explorada por Orlandi (2009).

O presente artigo busca discutir, então, o significado da universidade para jovens oriundos de classes populares que alcançaram o ensino superior. 0 texto divide-se em duas importantes discussões, em primeiro lugar fazemos um apanhado histórico da constituição das universidades, debatendo as relações de poder nela presentes e como a criação de planos de governo voltados para a democratização do acesso das classes na universidade foram fatores relevantes nesse processo. Em seguida, damos início à discussão dos resultados da pesquisa a partir das narrativas construídas pelos jovens colaboradores deste estudo, dividindo as temáticas em três pontos: 1) As diferentes significações apresentadas pelos estudantes sobre a universidade pública e universidade privada; 2) O Reconhecimento como forma concreta do "ser gente"; e 3) A universidade como projeto de vida para estudantes oriundos de classes populares. 


\section{A história da universidade no Brasil: os (des)caminhos do acesso democrático}

A história do surgimento das universidades no Brasil possui uma intrínseca relação com a constituição dessa nação enquanto sociedade de classes, desigual e por relações assimétricas de poder. Um panorama histórico alicerçado na ideologia meritocrática, a qual traz subjacente a crença na "igualdade de oportunidades", dada a suposta liberdade de acesso ao capital e à cultura produzidas socialmente, engendrando, assim, um país iníquo no que tange à garantia mínima das condições de oportunidades para a efetivação deste acesso (FREIRE, 2005; PATTO, 2015; SOUZA, 2009).

Nesse contexto, entendemos que o histórico das universidades no Brasil e, em especial, das universidades públicas (UP), do qual iremos tratar brevemente, é uma parte do que se compreende como história do ensino superior brasileiro. De modo que as instituições universitárias se apresentaram como um dos modelos de constituição dos estudos superiores. Diferenciandose, por exemplo, das escolas profissionalizantes e dos cursos isolados, cuja criação remonta à vinda da Família Real portuguesa em 1808 e tinham como anseio a formação superior em território nacional (BOTTONI; SARDANO; COSTA FILHO, 2013).

Dentre esses cursos isolados, podemos citar a criação do curso de Cirurgia, Anatomia e Obstetrícia, na Bahia; a Academia de Marinha, a Academia Real Militar, e a Academia de Medicina e Cirurgia, no Rio de Janeiro:

A proposta inicial seria a de termos aqui universidades similares àquelas encontradas em Portugal; no entanto, a estrutura social da colônia, além de distinta, via na educação um modo de ascensão, voltada principalmente à elite; portanto, colocando a classe popular de lado (BOTTONI; SARDANO; COSTA FILHO, 2013, p. 24)

Não obstante, Mendonça (2000) assume que o Ensino Superior tem a universidade como elemento de centralidade dos estudos superiores, cuja criação remonta à civilização ocidental e que no século XIX possuiu um papel significativo no processo de consolidação dos Estados Nacionais. É esta perspectiva histórica que irá embasar nossa discussão sobre as universidades públicas no Brasil.

No início do período republicano, diversos grupos e movimentos de intelectuais reivindicavam a criação de instituições universitárias no Brasil, com foco na pesquisa científica e com o propósito de agregar nestas as escolas profissionalizantes (BOTTONI; SARDANO; COSTA FILHO, 2013). Esse foi o período da institucionalização da universidade no Brasil que compreende os anos 1920 a 1940, no qual houve a incipiente criação das primeiras instituições universitárias públicas, a saber: Universidade do Rio de Janeiro, em 1920; Universidade de Minas Gerais, em 1927; Universidade de São Paulo (USP), em 1934; Universidade do Distrito Federal (UDP), em 1935; e a Universidade do Brasil (UB), em 1937 (MENDONÇA, 2000).

Ainda que tal processo de institucionalização das universidades no Brasil tenha expandido os estudos superiores pelo país, através da criação de novas 
instituições de ensino, o mesmo não foi suficiente para democratizar o acesso ao ensino superior. De forma que esta modalidade de ensino continuaria restrito às classes dominantes durante o período republicano, mesmo com o surgimento dos movimentos populares nas políticas educacionais e sua presença nos debates suscitados pela construção daquelas instituições. Assim sendo, não houve propostas que pensassem a democratização do acesso às universidades e, sobretudo, da ampliação dessa modalidade de ensino às massas populares.

Dessa maneira, deveriam ser as elites, exclusivamente, a produzir ciência e deter um poder-saber que reproduziria privilégios e lugares fixos de ocupação sociopolítica, em paralelo, tínhamos uma massa de espoliados por essa classe dominante.

Em uma análise política e social do período republicano, percebemos como a elite legitimava seus privilégios de classe, seja com o auxílio da repressão e controle policial, assim como do conhecimento científico que patologizava e criminalizava os comportamentos dos sujeitos empobrecidos. Além de marginalizá-los geograficamente, com o processo de urbanização e higienização das cidades, em lugares distantes dos centros urbanos, como a exemplo das construções das favelas. Com isso, manteve-se o status quo e mais distantes se encontravam às massas populares dos estudos superiores (PATTO, 1999).

Por conseguinte, as décadas de 50/60 apontaram situações peculiares, dentre estas: o aumento do número de instituições superiores e os debates em torno da questão da Reforma Universitária. No tocante a esta última, em 1961, a União Nacional dos Estudantes (UNE) realizava em Salvador o I Seminário Nacional de Reforma Universitária, cujas diretrizes básicas previam questões envolvendo as classes populares, todavia, não voltadas para a garantia do acesso nesse nível de ensino. Uma dessas diretrizes seria a abertura da universidade ao povo, por meio da extensão. Com o período ditatorial (19641985) e a ruptura do regime democrático, as universidades seguiram outro caminho em torno desta reforma (MENDONÇA, 2000).

Esse foi o contexto que viabilizou, posteriormente, a expansão das instituições universitárias de cunho privativo, as quais se expandiram pelo país em número e, sobretudo, em diversidade, pois diferenciavam das universidades públicas pela qualidade do ensino oferecido (MENDONÇA, 2000). Não obstante, essas instituições apresentaram, ao fim da década de 1970, um percentual equivalente a 62,3\% de matrículas (BOTTONI; SARDANO; COSTA FILHO, 2013).

De acordo com Bottoni, Sardano e Costa Filho (2013), as instituições privadas de ensino superior tiveram seu dinamismo focado no lucro que ocorreu a expensas da qualidade, em concomitância a uma crescente expansão de estabelecimentos isolados. Esse contexto foi reforçado, com uma crescente deterioração das universidades públicas brasileiras que tiveram, progressivamente, menores investimentos do Estado. Em consonância, esses autores nos mostram que ocorreu "o processo de expansão e privatização do sistema de ensino superior" (BOTTONI; SARDANO; COSTA FILHO, p. 32), com uma formação técnica focada no mercado laboral e a pesquisa, sob a lógica do setor produtivo, tornou-se produto requisitado pelas empresas. 
Acrescido a isso, os governos Fernando Collor de Mello (1990-1992) e Fernando Henrique Cardoso (1995-2003) foram marcados pela ausência de investimento estatal, no que tange ao âmbito da pesquisa científica e tecnológica. De modo que as instituições públicas de ensino superior foram deixadas à deriva, em especial os estudos graduados (BOTTONI; SARDANO; COSTA FILHO, 2013).

Em contrapartida, o governo de Luiz Inácio Lula da Silva (2003-2011) ensaiou propostas de expansão e democratização do acesso às instituições universitárias para os jovens das classes populares, oportunidades que, minimamente, possibilitaram que esses aspirassem aos estudos superiores. Assim, houve investimentos tanto no setor privado quanto nas universidades públicas, com a formulação e estruturação de programas como: o Fundo de Financiamento Estudantil (FIES), pela Lei no 10.260, de 12 de julho de 2001, disponibilizando aos alunos, que possuem vulnerabilidade econômica, um financiamento para ingresso nas instituições superiores do setor privado; o ProUni (Programa Universidade para Todos), instituído em 2004 como medida provisória, democratizou acesso ao ensino privado; o Programa de Apoio a Planos de Reestruturação e Expansão das Universidades Federais (REUNI), instituído em 2007, onde podemos notar uma descentralização das instituições universitárias, com destaque para abertura de novos estabelecimentos nos interiores dos Estados da federação (BOTTONI; SARDANO; COSTA FILHO, 2013; RÊGO; BENEVIDES, 2019).

Entretanto, Bottoni, Sardano e Costa Filho (2013) fazem uma crítica a esses programas governamentais que oportunizaram uma expansão das instituições privadas de ensino superior - nas quais cresceram o número de vagas, respondendo democraticamente as estatísticas -, de forma a afirmar que ao fim dos oito anos de governo, "o acesso à educação superior foi democratizado e que mais estudantes foram colocados nesse nível de ensino, no entanto, sem qualidade de formação garantida" (p. 40). Tal processo de inclusão dos jovens das classes populares nas instituições de ensino superior continua com novas propostas governamentais, que, minimamente, possibilitaram as condições de equidade no acesso aos estudos superiores para esses sujeitos. Dentre essas propostas, destacamos a política de cotas, no governo de Dilma Rousseff (2011-2016), sancionada por meio da Lei $\mathrm{n}^{\circ}$. 12.711, em 29 de agosto de 2012, que viabilizou o ingresso de estudantes das escolas públicas nas diversas universidades públicas brasileiras, cujo processo seletivo deveria reservar $50 \%$ das vagas a essa política (EVANGELISTA; MACIEL, 2019). Dessa maneira, presenciamos a construção de uma nova história para o ensino superior brasileiro, especificamente no que tange à democratização do acesso às universidades públicas aos jovens das classes populares, ou seja, "uma ação afirmativa na luta contra as desigualdades sociais" (EVANGELISTA; MACIEL, 2019, p. 117).

\section{Metodologia}

Para atingirmos nossos objetivos de pesquisa e nos aproximarmos dos discursos dos informantes, a metodologia utilizada foi qualitativa, posto que ela 
trabalha com o universo de significados, motivos, aspirações, crenças, valores e atitudes, o que corresponde a um espaço mais profundo das relações, dos processos e dos fenômenos que não podem ser reduzidos à operacionalização de variáveis" (MINAYO, 2001, p. 21-22).

Nesse sentido, utilizamos três formas de coleta de dados nesta pesquisa: formulário online, questionário - quando não foi possível utilizar o formulário online - e entrevistas semiestruturadas. Optamos pela utilização da entrevista semiestruturada posto que ela é constituída por um roteiro que contempla as temáticas que atravessam o objeto pesquisado, servindo, portanto, de guia, mas que também permite flexibilidade nas conversas, o que possibilita a absorção de temas e questões trazidas pelo/a informante (MINAYO, 2008).

Para iniciar nossa coleta, buscamos junto à Assistência Estudantil da UFC - Sobral permissão de acesso às informações dos nomes e e-mails dos estudantes bolsistas dos programas assistenciais Bolsa de Iniciação Acadêmica - PBIA e/ou Auxílio Moradia. Ao todo, identificamos 354 estudantes beneficiários por parte dos supracitados programas no Campus. Com base nos registros coletados, elaboramos um formulário online e enviamos para todos os estudantes em questão. O uso do formulário foi utilizado como ferramenta para selecionar aqueles que se adequavam como público da pesquisa, a saber: jovens oriundos de classes populares e que têm a mãe/figura materna como provedora do lar ou influenciadora para a sua entrada na universidade. Como resultado, recebemos 52 respostas e apenas 14 foram selecionados, posto que estavam dentro do perfil anteriormente descrito.

Devido à baixa porcentagem de respostas obtidas através do formulário online, elaboramos um questionário impresso (preservando semelhança de estrutura, conteúdo e critério) e aplicamos nas turmas ingressantes no semestre 2019.1, totalizando 177 questionários aplicados e destes 13 estudantes foram selecionados.

No tocante à participação das mães, conseguimos realizar somente 7 entrevistas, tendo os estudantes entrevistados como meio para estabelecer contato e checar a disponibilidade de suas mães para a participação na pesquisa. O número reduzido de mães ocorreu em virtude da recusa à realização da entrevista ou da dificuldade de locomoção dos pesquisadores até as residências das matriarcas (municípios distantes da sede UFC/Sobral).

Desse modo, participaram desta pesquisa 27 estudantes da UFC - Sobral (com idades entre 17 e 27 anos) e 7 mães provedoras e/ou influenciadoras para a entrada de seus filhos na universidade (com idades entre 39 e 57 anos), totalizado 34 entrevistas. Entretanto, considerando os objetivos deste estudo, utilizaremos somente as entrevistas dos estudantes, que tinham um roteiro voltado para temáticas relacionadas à trajetória de vida desses sujeitos, enfocando desde o início da escolarização até o ingresso na universidade, bem como suas experiências nessa instituição e suas perspectivas quanto ao futuro.

Para o processamento dos dados da pesquisa, utilizamos o software IRAMUTEQ (Interface de $R$ pour lês Analyses Multidimensionnelles de Textes et de Questionnaires) recorrendo à ferramenta da Classificação Hierárquica Descendente (CHD), que através de uma análise que considera frequência e 
posição no texto, possibilita a criação de classes de palavras e a identificação de trechos de textos associados entre si e usados em contextos semelhantes (CAMARGO; JUSTO, 2013).

Com o apoio da CHD, foram construídas categorias correspondentes às classes de palavras geradas pelo programa. Para Minayo (2001), as categorias podem ser estabelecidas em diferentes fases da pesquisa, assim, optamos pelo estabelecimento das categorias de análise após a realização da coleta dos dados, por meio do critério léxico do software utilizado. Nesse sentido, a análise do IRAMUTEQ estabeleceu 4 classes, mas considerando os objetivos deste estudo, nos debruçaremos apenas sobre a classe 1, denominada de "Significados da Universidade".

Para uma análise crítica dessa classe, utilizamos a metodologia da Análise do Discurso, que conforme Orlandi (2009), busca uma compreensão do processo de produção dos sentidos e sua relação com a ideologia, considerando que as falas dos sujeitos são efeitos de sentido atravessados por condições determinadas (ORLANDI, 2009).

Ademais, obedecendo a todos os princípios éticos e legais presentes nas Resoluções CNS 466/12 e 510/16, o projeto foi submetido à apreciação do Comitê de Ética em Pesquisa da Universidade Estadual Vale do Acaraú e aprovado sob o parecer número 3.685.722.

\section{Resultados e discussões}

No tocante ao processamento realizado pelo IRAMUTEQ, tivemos um corpus geral constituído por 27 textos, separados em 2.532 segmentos de texto (ST), com aproveitamento de 2.110 STs (83,33\%). Emergiram 88.907 ocorrências (palavras, formas ou vocábulos), sendo 5.405 palavras distintas e 2.510 com uma única recorrência. O conteúdo analisado foi categorizado em 4 classes: Classe 1, com 585 ST (27,73\%); Classe 2, com 312 ST (14,79\%); Classe 3, com 597 ST (28,29\%); e Classe 4, com 616 ST $(29,19 \%)$.

Para a análise proposta teremos como foco a Classe 1, intitulada como Significados da Universidade, constituída por palavras e radicais no intervalo entre $x^{2}=3,97$ (Chance) e $x^{2}=175,7$ (Universidade). Essa classe é composta por palavras como Universidade ( $x^{2}$ \&gt; 175,7); Curso ( $x^{2}$ \&gt; 94,79$)$; Querer ( $x^{2}$ \&gt; 84,05); Faculdade ( $x^{2}$ \&gt; 81,75); UFC ( $x^{2}$ \&gt; 79,92); Sonho ( $x^{2}$ \&gt; 60,07); Entrar ( $x^{2}$ \&gt; 50,05); Melhor ( $x^{2}$ \&gt; 46,05); Oportunidade ( $x^{2}$ \&gt; 36,36); Vida ( $x^{2}$ \&gt; 31,59); Futuro ( $x^{2}$ \&gt; 22,51); e Orgulho ( $x^{2}$ \&gt; $22,47)$.

Assim, a partir dos segmentos de texto pertencentes a essa classe, e considerando os discursos dos estudantes entrevistados, construímos nossa análise a partir de três dimensões: a) a contraposição entre a Universidade Pública e o Ensino Superior Privado; b) a Universidade como estando vinculada a uma busca por reconhecimento e orgulho; e c) a Universidade como Projeto de Vida para esses jovens.

4.1 A outra face da escolha pela universidade pública: o ensino superior privado (ESP) e suas impossibilidades aos jovens das classes populares 
Os jovens entrevistados, quando questionados sobre os motivos que os levaram à escolha pela universidade pública, trouxeram em suas narrativas, em linhas gerais: o não desejo, o preconceito, as inviabilidades econômicas, a não qualidade do ensino, a facilidade no ingresso e o menor reconhecimento no mercado laboral das instituições de ensino superior privado (ESP).

Nessas narrativas é possível perceber que a escolha pela universidade pública esteve imbuída da negação das instituições privativas superiores, expressa em suas impossibilidades aos jovens das classes populares, cujos significados atribuídos à escolha daquela constroem-se em contraposição a essas. Esses significados são constitutivos de discursividades, por meio das quais iremos compreender os "processos de produção de sentidos e de constituição dos sujeitos em suas posições" (ORLANDI, 2009, p. 72).

Desse modo, universidade pública e universidade privada se apresentam como dimensões do mesmo processo - escolha pelos estudos superiores. Em outras palavras, compõem uma mesma unidade dialética. Ao mesmo tempo, serão apreendidas como fenômenos historicamente produzidos (OLIVEIRA; QUINTANEIRO, 2003).

Essas instituições de ensino superior (IES), lidas metaforicamente como faces do mesmo processo, produzem os significados dos discursos dos nossos sujeitos de pesquisa, os quais advindos de contextos empobrecidos trazem consigo incertezas históricas de aspiração aos estudos superiores, que aumentam quando se trata do ensino superior privado. Assim como trazido por Piotto (2007, p. 2):

enquanto nas universidades públicas há, proporcionalmente, maior número de estudantes pobres, nas instituições particulares de Ensino Superior ocorre o contrário, existindo maior porcentagem de alunos provenientes de lares com renda elevada.

Em contraposição, dois jovens entrevistados narram que, em seus entendimentos, uma parcela dos estudantes, egressos da escola pública, encontram-se nas instituições privadas de ensino superior, o que os motiva, indo na contramão, à escolha pela universidade pública:

Porque eu venho de uma cidade que a gente nunca vê pessoas em universidades, a maioria é em faculdades particulares que tem nem condições de pagar, aí eu acho que é a pessoa ver uma coisa e ter vontade de melhorar a sua vida, dá um passo a mais na sua vida, modificar tudo, diferenciar (V. F., 18 anos).

Eu tenho preconceito contra o ensino privado, eu reconheço que tenho, é... eu observo que as pessoas que são do ensino público, que saem das escolas públicas, elas tendem a migrar, quando elas desejam fazer um ensino superior, elas tendem a migrar para o ensino particular, porque o processo seletivo é mais fácil, por uma série de outros fatores (E. S., 20 anos).

O jovem E.S alegou que o preconceito com o ensino ofertado nas universidades privadas, somado com as facilidades de ingresso nas mesmas, 
ambos foram fatores motivadores para sua opção pelo ingresso nas instituições públicas de ensino superior, mesmo com sua suposta dificuldade de escolarização:

Eu coloquei na minha cabeça que eu não ia fazer isso, eu ia pegar as minhas dificuldades, a minha defasagem na escola, e que eu superar, que eu ia tentar superar isso, e que eu ia tentar, na verdade, eu sabia que eu queria a UFC (E. S., 20 anos).

Assim posto, o que este último jovem talvez não perceba sobre esse ingresso "fácil" nas instituições superiores privadas pelas pessoas que saem das escolas públicas, é que o mesmo foi oportunizado pela formulação, estruturação e operacionalização de programas governamentais que ampliaram as vagas, com a criação de novos estabelecimentos de ensino, que facilitaram o acesso aos estudos superiores para os jovens das classes populares. Dentre tais programas, podemos citar o ProUni (Programa Universidade para Todos) e o Fundo de Financiamento Estudantil (FIES).

De acordo com Bottoni, Sardano e Costa Filho (2013), uma proposta de democratização do acesso ao ensino superior que ocorreu a expensas da qualidade do ensino, pois se priorizava, nessas circunstâncias, menos a qualidade do que o aumento no número de matrículas dos cursos superiores.

Em consonância, as inviabilidades econômicas constituíram as narrativas dos sujeitos desta pesquisa acerca do ingresso no ESP. Embora, amalgamadas com a visão negativa acerca da qualidade do ensino nessa modalidade de ensino:

[...] tem aquele pensamento que universidade pública é melhor que a privada, e eu não teria dinheiro para pagar à privada, não me interessa em nenhum aspecto, porque o que tem aqui, não tem na outra (K. S., 18 anos).

[...] jamais teria como eu pagar um curso, tinha que ser de graça, por isso a UFC, e eu também queria porque eu acreditava que aqui era uma universidade de qualidade (L. C., 27 anos).

[...] eu me via numa federal, eu tinha um certo preconceito de estudar em uma particular, até porque meus pais pagaram a vida toda escola particular, era o mínimo que eu podia fazer, eu fiz uma na minha cidade mas era porque eu estava num momento crítico, mas quando eu saí o meu pai nem conseguiu terminar todas as mensalidades (H. M., 26 anos).

Assim colocado, percebe-se a construção de uma visão negativa do ESP que traz subjacente o discurso - mesmo que nossos informantes não consigam formular - de que não adianta garantir o acesso, se o mesmo não estiver atrelado às estratégias de permanência dos discentes nos cursos superiores (EVANGELISTA; MACIEL, 2019).

Em consonância, o Programa Nacional de Assistência Estudantil - PNAES, consolidado pelo Decreto n. $7.234 / 2010$ se propõe a minimizar, por um lado, os impactos das desigualdades econômicas e sociais no tocante ao acesso e à permanência nas instituições de ensino superior, por outro, as iniquidades de 
escolarização, visando a diminuir as taxas de evasão e repetência nos cursos superiores (BRASIL, 2010). Desse modo, a forte presença desse programa nas universidades públicas (RÊGO; BENEVIDES, 2019; SILVA; LEME, 2019) alimenta, nos jovens entrevistados, a certeza de poderem prosseguir seus estudos e, assim, escolhem ingressarem nas universidades públicas.

[...] pela oportunidade de pessoas que não tinham condições financeiras de poderem estar cursando algo. Além de que eu já ouvia falar bem da UFC, da questão da estrutura dela e de como ela trabalha, das oportunidades que ela dá pros alunos e outras questões (F. L., 20 anos).

[...] é uma faculdade que tem muito auxílio, muita bolsa, e isso te ajuda muito e também a questão da federal, me motivou muito pôr o quanto você é reconhecido, tipo a faculdade te dá um diploma e não é só um papel, ela realmente de proporciona estágio, essas coisas. (V. F., 18 anos).

Destarte, as histórias de ingresso de jovens das classes populares nas universidades públicas, entendidas como trajetórias de "Sucesso Escolar" (LAHIRE, 1997; PIOTTO, 2009), não podem prescindir da compreensão dos significados que são produzidos por esses quanto à escolha pelos estudos superiores. Esses significados, no caso dos jovens entrevistados, constituíramse de discursos atrelados à negação das instituições de ESP que, resumidamente, sob a égide da dialética exclusão-inclusão (SAWAIA, 2017), não são percebidas como espaços acessíveis, mesmo quando o acesso é oportunizado. Todavia, torna-se necessária a construção de estratégias que possibilitem também a permanência desses jovens nessas instituições, quiçá, assim, possamos começar a construir significados sobre a democratização do ensino superior brasileiro, em sua totalidade dialética.

4.2 Jovens de classes populares na luta por reconhecimento: possibilidades de "ser gente"

A juventude sobre a qual nos debruçamos nesta pesquisa abarca sujeitos provenientes de classes populares que encontraram por meio da educação uma das possíveis formas de romper com o ciclo de pobreza presente em seus contextos, podendo, então, a partir da entrada na universidade, buscar a ascensão social, que aparece nas suas falas como o entendimento de "ser gente" ou "ser alguém". Essas percepções tomam formas atreladas a uma noção de reconhecimento que, por sua vez, busca uma posição de utilidade e produtibilidade, de modo que os sujeitos considerados reconhecidos consigam se sobressair em seu contexto e ascender socialmente (SOUZA, 2003). Assim, torna-se importante para essa discussão que entendamos o que significa essa noção de "ser gente" para esses jovens e porque essa percepção influencia em certo grau em suas escolhas de seguir com os estudos para além de onde seus pais conseguiram chegar.

É perceptível nas falas dos sujeitos a conexão de sentidos que fazem quanto à ideia do "ser gente" como alguém que possui sucesso, futuro ou melhores condições de renda e emprego. A família, tanto quanto a escola, dispõe 
de uma possibilidade de transmissão de informações que, atrelada a uma carga afetiva e efetiva, possui influência nos sujeitos quanto a recepção desse conhecimento (PIOTTO, 2009; PIOTTO, 2010), como é apresentado por alguns estudantes:

Primeiro eu ouvi muito o meu pai dizer que se ele tivesse estudado ele taria sendo alguém na vida. Porque... Eles sempre influenciaram muito, tanto eu e o meu irmão, a estudar pra... Ter um futuro melhor, né? (E. L., 20 anos)

Porque até hoje o que eu sempre escutei, né? E que eu aprendi, é que eu só vou virar gente se tiver a graduação... e que eu só vou poder ganhar mais de $R \$ 300,00$ reais no mês se eu fizer a graduação, né? Vai ser mais fácil arranjar emprego e... ter uma condição de vida melhor. Foi o que foi me dito até entrar na universidade (T. M., 19 anos).

Desde quando eu era pequeno que minha mãe, meu pai quando era vivo, eles falavam de que eu tinha que estudar para ser alguém na vida, que eu tinha que estudar pra não arrumar um emprego qualquer e ser igual eles, ser igual eles no sentido de não ter uma profissão fixa (W. D., 20 anos).

Dessa forma, percebe-se que existe um processo complexo de incorporação, que se torna possível através da transmissão de aspectos socialmente produzidos pelos quais esses jovens estão envoltos, que traduzem uma série de ideias sobre o "lugar" do sujeito pobre (PIOTTO, 2009; PIOTTO, 2010) e que influenciam no estabelecimento dessa busca por "ser alguém", que está atrelada diretamente a tomar para si responsabilidades, como o trabalho e o estudo, que mais a frente estarão ligadas à ideia de tornar-se adulto (BOURDIEU, 1983; PAIS, 1990).

Diante disso, percebemos que os jovens apresentam queixas de seus pais quanto à falta das "responsabilidades de adultos", visto que essas responsabilidades são formas de ocupação de um sujeito, que se caracterizam através do trabalho ou do estudo e possuem o poder de estabelecer a possibilidade de ser ou não reconhecido (BOURDIEU, 1983; PAIS, 1990).

Eles só falavam que a gente tinha que ser alguém na vida. E ainda mais, eu acho que era no sentido de ter um emprego. Porque na visão da minha mãe, pelo que percebo, uma pessoa que não tem nada e não quer nada na vida é uma pessoa desempregada, uma pessoa vagabunda como ela chama (W. D., 20 anos).

Assim, os meus pais sempre me incentivaram a estudar, sempre me incentivaram que o estudo é a porta pra vida adulta, ser mais... ter uma melhor qualidade de vida e eu sempre fui assim (A. N., 21 anos).

[...] desde cedo, muito cedo mesmo, desde que eu tenho minhas primeiras memórias, eu tenho minha mãe me cobrando, não me cobrando pressionando, mas dizendo né? Que estudo é a forma mais... certa de ascensão social, e aquilo ficou em mim (A. L., 26 anos). 
Nesse contexto, vislumbramos uma forma de ascensão financeira e social que está atravessada pelas ideias de futuro e responsabilidade e que exemplificam o que Souza (2003) irá chamar por ideologia do desempenho. Para o autor, a ideologia do desempenho retrata uma forma de legitimação da desigualdade e que está baseada em uma tríade meritocrática, que engloba qualificação, posição e salário. Nesse sentido, é notório que as formas de mudanças de contextos para jovens em situações de vulnerabilidade socioeconômica tornam-se ainda menores, visto que através da ideologia do desempenho, o sistema de seleção desses jovens, tanto no mercado de trabalho quanto no espaço acadêmico, afunila suas possibilidades (SOUZA, 2003).

Paralelo a este conhecimento, se torna importante destacar quais são as possíveis consequências frente a essa privação de oportunidades naturalizadas às classes populares. Trataremos, então, do que Honneth (2003) apresenta como reconhecimento denegado. Para o autor, o reconhecimento é o ato mais justo para definir aqueles que podem compreender as normas sociais. Desse modo, o autor divide em três as formas de reconhecimento intersubjetivo: o amor, o direito e a estima social, para as quais irão existir as três formas de desrespeito: maus-tratos, privação de direitos e degradação, respectivamente. Assim, o autor apresenta a lógica de que o sujeito que tem uma privação de seu reconhecimento possui uma grande capacidade de mobilização e transformação social, o que ele apresenta como luta por reconhecimento.

De acordo com Honneth (2003), a luta por reconhecimento caracteriza a reivindicação dos direitos recusados por aqueles que, afetados pela seleção imposta através da ideologia do desempenho, não se percebem enquanto partes ativas da sociedade, consequentemente, não estão inclusos no ser gente. Ademais,

é preciso haver a mediação de uma pessoa ou situação próxima socialmente para que um estudante das camadas populares passe a considerar a possibilidade de ingresso em uma universidade pública (PIOTTO; ALVES, 2016, p. 145).

Visto que, devido às várias vezes que não foi apresentado a esses jovens a possibilidade em sonhar com seu sucesso escolar, a motivação para essa transformação social pôde surgir a partir dos desejos dos pais, da recusa social em considerá-lo pertencente de um espaço ou de outros fatores que podem vir a ser decisivos quanto a essa mobilização. Podemos ter o vislumbre desses conceitos a partir dos relatos que nos foram apresentados, quando nos deparamos com o desejo dos jovens de "ser melhor", ou provar uma competência pessoal, como destacam alguns estudantes:

[...] começou por uma questão de querer, queria mostrar para a galera que pensava de forma negativa pra mim que eu poderia ser alguém e eu ia a universidade como essa forma de uma forma honrosa de certa forma (L. V., 20 anos).

[...] meu tio foi um próprio fator... uma influência para eu querer uma universidade porque minha mãe sempre o colocou como uma pessoa que teve sucesso social, como sucesso financeiro, e era algo que tinha que ser 
seguido, mesmo o ingresso na universidade não sendo comum na minha família (L. A., 20 anos).

[...] minha mãe queria que eu fosse diferente, que eu fosse diferente dessa família. Daí o pessoal já tinha essa visão negativa e por mim eu não estava preocupado mesmo, então deixaram de querer, de saber, de se importar. Mas minha mãe, minha mãe e minha prima não, elas ainda continuavam a ter esperança de que eu conseguiria voltar a estudar ( $L$. V., 20 anos).

Portanto, observa-se que a concretização dessa reivindicação toma importância tanto para os estudantes quanto para seus pais, podendo ser expressa como orgulho. A dimensão do orgulho surge como resposta ao sucesso dessa reivindicação, tomando maior frequência a partir dos pais em relação aos filhos:

Eu acho que além de orgulho, eu acho que... talvez de dever cumprido, porque acredito eu que pra ela (mãe) e pro meu pai é uma coisa mais importante que eles queriam, que ela queria, que ele queria também que era que eu entrasse na universidade, pra mim né, sobre a universidade, acho que foi muito importante pra ela. [...] Porque talvez outras pessoas tenham dito para ela que ser gente também é só se entrasse na universidade, né? Talvez tenha dito um pouco mais duro para ela e talvez ela acredita até hoje (T. M., 19 anos).

Muita coisa, significa um orgulho para minha família, um orgulho para mim mesma, é como... é como se tipo, todo o estudo que eu tivesse passado minha vida toda tivesse valido a pena, para estar aqui hoje ( $M$. M., 18 anos).

Para mim significa muito mesmo, eu tenho muito orgulho de mim. O que para muitas pessoas pode não ter significado, para mim foi muita superação mesmo, foi uma conquista muito grande (L. C., 27 anos).

Assim, percebemos que há uma inquietação quanto à conquista de poder estar na universidade, algo que se torna quase inacreditável em vista da não espera pela aprovação, já que, em razão do contexto, os estudantes não cogitam a possibilidade de seu sucesso escolar (PIOTTO; ALVES, 2016). A universidade representa, então, um símbolo de conquista para esses jovens e para seus pais, de modo a promover a recuperação de sua autoestima antes impedida pela denegação de seu reconhecimento, que produziu um modo de mobilização social e que os permite, através dessa demanda, transformar suas histórias e a de pessoas que envolvem seu contexto, além de promover a sensação de vitória nesses indivíduos (ZAGO, 2006).

4.3 Projeto de vida e a caminhada rumo às possibilidades de futuro: uma estação chamada universidade pública

A partir dos discursos dos estudantes entrevistados, pudemos apreender que o ingresso no ensino superior público também está vinculado à construção dos projetos de vida desses jovens. Assim, entendemos o conceito de Projeto de Vida não como um fenômeno inteiramente subjetivo, mas como uma construção 
embasada em experiências socioculturais, fruto daquilo que é vivenciado dentro do campo de possibilidades objetivas de cada sujeito, tendo em vista uma busca pela transformação de seu contexto (CATÃO, 2001; DAMASCENO, 2001; HURTADO, 2012; TEIXEIRA, 2005).

Considerar o contexto em que esses jovens estão inseridos é refletir também sobre a realidade social, econômica e política da Região Nordeste, bem como a do Brasil em geral, que parece apontar que somente através da escola, e posteriormente, da inserção no ensino superior, é que os jovens pertencentes às camadas populares poderão construir sonhos de um futuro melhor, diferente daquilo que foi conquistado por seus pais no presente (FERNANDES, 2003), conforme trazido por um dos estudantes:

\footnotetext{
É... assim, por causa da minha mãe ter baixa escolaridade, ela não conseguiu terminar o fundamental, ela sempre questionou muito, questionou não, ela sempre cobrou muito a gente, eu e o meu outro irmão, que tem um ano a menos que eu, essa questão de que estudar era uma saída pra... pra... como é que eu posso dizer? Pra... qualquer situação de vulnerabilidade, né? Porque em cidade pequena você não tem muita opção de emprego, você não tem muita opção de ascensão social, né? Então ou você olha para um horizonte um pouquinho é... mais complicado, que no caso é estudar, ou você... É praticamente condenado a viver sempre naquela situação (A. L., 26 anos).
}

Diante desse contexto, nos questionamos que condições são necessárias para que esses jovens consigam vislumbrar um deslocamento daquilo que é instituído para sua classe, através dos obstáculos que cercam a entrada no ensino superior, e criar estratégias que possibilitem a transformação de seus contextos através da concretização dos seus projetos de vida, tendo como meio a entrada e permanência na universidade pública.

Essa discussão nos remete ao projeto de modernidade trazido por José de Souza Martins (2011), pois, como fala o autor, mesmo que todos devam se enquadrar nesse projeto, a modernidade apenas anuncia as alternativas de vida que parecem possíveis e disponíveis para qualquer sujeito, entretanto, nem todos conseguem alcançar esse projeto, pois mais do que saber das possibilidades, é necessário que se tenha recursos para que o possível se transforme no real. Acreditamos então que para que a UFC fosse tida como uma possibilidade de futuro para os estudantes entrevistados, foram necessárias algumas "condições" que nada têm de "naturais". Dentre essas condições, destacamos primeiramente a presença da UFC em Sobral, possibilitada através de ações voltadas para a interiorização das universidades, o que têm contribuído para a inserção de jovens oriundos do interior do estado no ensino superior público (ANDRIOLA; SULIANO, 2015), somando o reconhecimento que uma universidade federal carrega e a proximidade com municípios afastados da capital cearense, como relatado pelos estudantes:

A UFC sempre tem aquela coisa que a gente tem um respaldo maior, por ser federal e tal, mas eu acho que foi mesmo a UFC porque era a única que eu ia lançar no ENEM, que era a mais próxima da cidade de Sobral, acho que não tinha outra (E. S., 20 anos). 
A UFC Sobral foi uma escolha por ser a Universidade Federal do Ceará e por eu saber que ir pra Fortaleza seria uma questão ainda maior. Então Sobral, pela proximidade com a minha cidade, foi a cidade escolhida (L. A., 20 anos).

Além desse fator, diferentes autores (HURTADO, 2012; OLIVEIRA, 2000; SANTOS, 2009; TEIXEIRA, 2005) apontam que a concretização do projeto de vida de um sujeito depende essencialmente do suporte de uma "rede social", uma rede de apoio. Desse modo, esse suporte pode vir da família, da escola, de professores, ou até mesmo de outros colegas, algo que muito se repetiu nas narrativas dos entrevistados como um elemento que pôde proporcionar influência e apoio para que a continuidade das trajetórias escolares desses estudantes fosse possível:

Minha mãe sempre me apoiou nessa questão do estudo, ela podia não estar estudando comigo, não podia estar ali do meu lado, mas ela sempre fez de tudo pra eu poder conseguir estar estudando, poder ir para uma escola. Em momentos em que eu não queria mais saber de estudar ela queria que eu estudasse porque ela sabia que aquilo de certa forma ia ser importante na minha vida (F. L., 20 anos).

Quando você tem bons professores, eles te dão uma visão de mundo diferente e tipo questão de aula e de trabalhar e mais, os professores te incentivam à procurar uma coisa melhor (V. F., 18 anos).

Considerando esses relatos, entendemos então que o rompimento com trajetórias socialmente determinadas a partir do contexto em que esses jovens estão inseridos se configura como uma conquista que é bem mais do que resultado de um "esforço individual", mas como fruto de um contexto familiar e social.

Ademais, um Projeto de Vida também se constitui como um objetivo de futuro que dá sentido à vida do sujeito, motivando interesses e ações que busquem a realização de suas metas (HURTADO, 2012). Percebemos assim que os projetos de vida desses estudantes estão geralmente relacionados ao estudo e ao trabalho, especialmente como possibilidades de transformar a vida de suas famílias e superar a condição de vulnerabilidade social, passando necessariamente pela formação universitária:

Primeiro o fato que eu gosto muito de estudar (risos), e segundo que eu queria ter um futuro. Aí... pronto. E eu sempre quis... fazer faculdade... desde pequenininho. Por isso... Ter futuro? É... conseguir estabilidade. Principalmente financeira, porque hoje em dia, né? Está muito... complicado, e também, é mais também para ajudar lá em casa (C. D., 18 anos).

Então, assim, a questão do que significa a universidade para mim, eu penso mais na minha mãe e no meu pai. Para mim a universidade... é a oportunidade de... de poder mudar de vida, basicamente isso. Se eu for resumir, é a oportunidade de mudar de vida (T. M., 19 anos).

Porque eu sempre gostei de estudar e queria continuar, é importante a gente se formar, sei lá. Para ser um bom profissional futuramente, ter 
uma vida melhor, porque a gente da (cita a cidade de origem) é muito difícil, aí alguém assim... sei lá, é importante. Me sinto importante pela primeira vez na vida (M. M., 18 anos).

Considerando essa última fala trazida, concordamos com Damasceno (2001, p. 15) no sentido de que "a crença no poder da educação como instrumento de mobilidade social, se por um lado, encerra uma possibilidade real de melhoria das condições de vida, por outro, contém um forte componente ideológico". Sendo assim, como afirma Orlandi (2009), o sujeito muitas vezes não sabe como suas falas se constituem, mas elas são sempre carregadas de sentidos, de uma relação com a exterioridade, a partir das condições e do contexto sócio-histórico-ideológico em que são produzidos.

Nesse sentido, sabemos que não só para esses jovens, mas para toda uma sociedade que partilha da "racionalidade ocidental", que segundo Souza (2003), está embasada na tríade meritocrática: qualificação, posição e salário, ter acesso ao ensino superior quer dizer bem mais que conseguir um diploma, assim como ter um trabalho quer dizer bem mais do que receber um salário, representa uma identidade e um lugar social, estando relacionado com a autoestima e o reconhecimento (SANTOS, 2009; TEIXEIRA, 2005). Evidenciando também o quanto o que é dito por esses estudantes também tem relação com aquilo que constitui essa ideologia, com o que é dito também em outros lugares, por diferentes sujeitos, ou mesmo com aquilo que não foi dito, mas que ainda assim constitui o discurso (ORLANDI, 2009). Desse modo, para esses estudantes, a continuidade dos estudos através da universidade aparece como a única forma de conseguirem ter um trabalho socialmente digno e um futuro melhor.

Diante disso, percebemos que o projeto de vida se evidencia bastante no pensamento que esses estudantes têm sobre o futuro, considerando os desejos do presente e as faltas que pretendem preencher. É nesse contexto que a trajetória no ensino superior passa a ser, em muitos casos, impulsionada não apenas pelo desejo de ascensão financeira e realização individual, mas também por um projeto de mudança social (OLIVEIRA, 2000):

A questão de eu querer muito mudar a minha realidade, porque eu venho de uma cidade que a gente nunca vê pessoas em universidades, a maioria é em faculdades particulares que tem nem condições de pagar, aí eu acho que é a pessoa ver uma coisa e ter vontade de melhorar a sua vida, dá um passo a mais na sua vida, modificar tudo, diferenciar (V. F., 18 anos).

Assim, essa transformação da realidade mediada pela entrada na universidade também significa uma mudança subjetiva do indivíduo em relação ao mundo (TEIXEIRA, 2005):

Para mim é como se fosse a realização de um sonho e o começo de uma história, porque entrar foi um marco muito importante na minha vida, que mudou minha vida em diversos aspectos e está aqui é como se tivesse ampliado, sabe? Ampliado todo o meu campo de vivências, ter ampliado a minha visão de mundo, que agora é completamente diferente do que eu tinha antes, e eu acho que é isso. Além da realização de um sonho, essa expansão (V. S., 21 anos). 
Consideramos então que estar na universidade significa a transformação de diferentes âmbitos da vida desses sujeitos, tanto relacionados aos aspectos subjetivos, tais como a sensação de reconhecimento e a mudança de visão em relação ao mundo, quanto relacionados as possibilidades objetivas de transformarem seus contextos, tanto familiar quanto social. Nesse sentido, a vida como universitários parece possibilitar, por fim, que esses jovens avaliem suas realidades e elaborarem estratégias para que seus projetos de vida sejam concretizados (TEIXEIRA, 2005), o que faz com que esses indivíduos possam ser capazes de administrar o seu próprio destino, através da construção de um sonhado e planejado "futuro melhor":

Agora que eu estou começando a viver de fato. Viver, traçar minha própria história, no sentido de que eu estou construindo algo agora para colher futuramente (F. W., 20 anos).

Por conseguinte, essa possibilidade de traçar suas próprias trajetórias também nos remete à discussão sobre empoderamento conduzida por Joice Berth (2018). Como argumenta a autora, é fundamental considerar que ninguém se empodera individualmente, posto que o empoderamento se constitui como um instrumento de luta por emancipação e superação das desigualdades, e portanto, como um projeto produzido coletivamente. Com isso, entendemos que os jovens entrevistados puderam se empoderar no contexto de políticas públicas educacionais administradas por governos progressistas, tendo também toda uma rede de suporte para que sua caminhada até o ensino superior fosse possibilitada.

Diante dos discursos desses estudantes, entendemos que a conquista de um "bom futuro" através da construção de um projeto de vida que esteja vinculado à entrada no ensino superior, passa pelo conhecimento adquirido na universidade, pelo reconhecimento por ter alcançado o ensino superior, e posteriormente ter a possibilidade de exercer um trabalho socialmente valorizado, pela possibilidade de adquirir bens materiais, posto que almejam a saída de uma condição econômica desfavorável, e por fim, por uma mudança que é bem mais que financeira ou individual, mas que tem relação com uma verdadeira transformação social.

\section{Considerações finais}

Na reconstrução histórica da Educação superior brasileira, notamos o quanto seu papel estava exclusivamente em formar os jovens das classes dominantes - que não por coincidência, eram as que detinham o poder político e econômico no país. Num espaço fomentado à produção do conhecimento científico, encontrava-se, preponderantemente, uma classe que percebia no acesso aos estudos superiores a manutenção de seus privilégios.

Desse modo, os jovens empobrecidos se viam, cada vez mais, distantes dos estudos superiores e, em muitos casos, não lhes era apresentado como opção o desejo às carreiras universitárias. Um panorama que se modificou com a implantação, a partir dos governos progressistas, de programas que minimamente diminuíram as barreiras histórico-sociais e da emergência de 
políticas de equidade que ampliaram não somente as vagas dos cursos superiores, mas oportunizaram aos jovens empobrecidos as condições de acesso e permanência nas diversas universidades públicas. Essas foram iniciativas governamentais que deram uma nova constituição ao ensino superior brasileiro, cujo compromisso democrático deve almejar a emancipação dos sujeitos por meio da Educação.

$\mathrm{Na}$ pesquisa apresentada, notamos que os jovens entrevistados perceberam no acesso às universidades um dos caminhos possíveis para a superação dos condicionantes dos contextos de pobreza em que se perceberam inseridos. Assim, entendemos essas trajetórias como sendo fruto de uma construção coletiva baseada em diferentes aspectos, tais como: a oportunidade oferecida através da interiorização das universidades e a importância de uma rede de apoio capaz de dar suporte para que a entrada no ensino superior fosse considerada como possiblidade. Nesse sentido, os significados da universidade para esses estudantes estão vinculados a uma busca pela superação da situação de pobreza e de exclusão social, seguindo uma trajetória que começa pela entrada e conclusão do ensino superior para que em seguida se possa conseguir um bom emprego, ser independente, ajudar a família e se sentir realizado.

A máxima estava em ascender aos estudos superiores, com o intuito de mudar os seus condicionantes econômicos e sociais e de seus familiares e, assim, serem sujeitos na luta pela transformação social, ou seja, (trans)formarse nas universidades públicas para serem exemplos aos demais de que é possível almejar o ensino superior e serem atuantes na luta pela garantia dos direitos sociais.

Nesse ínterim, os jovens entrevistados trouxeram, a partir de seus relatos, o quanto a universidade pública tem o papel de transformar socialmente as pessoas, uma formação que emancipa mediante a viabilidade do acesso à produção de saber, pois acreditamos no poder que o conhecimento tem para mudar vidas. Além disso, reiteramos a crença de que oportunizar que estudantes, histórico-socialmente distanciados do ensino superior, possam ter a universidade pública como projeto de vida é um desafio para as políticas públicas de Educação, constituindo-se como medida governamental necessária para qualquer sociedade com pretensão de luta pela justiça social. Dito isso, não queremos aqui afirmar que a universidade é o único, ou mesmo, o melhor caminho para todos os jovens, todavia, acreditamos no potencial da educação como meio para a transformação social e a superação das desigualdades.

Diante do exposto, percebemos que os significados construídos pelos jovens entrevistados, concernentes ao ingresso numa universidade pública, estiveram atrelados, por um lado, à superação dos contextos de empobrecimento que se encontram inseridos e, por outro, como caminho para consolidação de estratégias para transformação social. De modo que ter acesso aos estudos superiores apresenta-se como ato político que modifica diversas dimensões da vida desses sujeitos. Nesse sentido, não se trata somente do desejo de prolongamento dos estudos, mas, sobretudo, de emancipar-se socialmente por meio da Educação.

Não obstante, os significados construídos pelos jovens das classes populares acerca da universidade pública tiveram relação intrínseca com as 
políticas públicas de Educação, a saber: afirmativas, assistenciais e de equidade. São propostas governamentais de suma importância para pensarmos o caráter democrático das instituições públicas de ensino superior no Brasil. Neste estudo, não conseguimos nos prolongar nas construções dos significados da permanência para os sujeitos empobrecidos, dado aos limites metodológicos e ao objetivo norteador da discussão. Compreender quais os contextos que viabilizam a permanência dos jovens das classes populares nas universidades públicas é uma questão relevante, mas que não conseguimos responder nesta pesquisa, mesmo acreditando que as políticas de Assistência Estudantil tenham alguma implicação nisso. Por isso, é mister salutar o fortalecimento e a garantia dessas políticas públicas como direito social dos sujeitos.

Por fim, sugerimos a construção de pesquisas que versem sobre esse questionamento, abrangendo os significados da permanência nas universidades públicas para os jovens das classes populares, ou mesmo, quais os contextos que viabilizam e, sobretudo, quais sujeitos e de que forma permanecem. Talvez, assim, possamos começar a construir significações que denotem a democratização dos estudos superiores em sua totalidade, pois acreditamos que acesso e permanência se constituem como direito social e devem ser garantidos como ato político na luta por transformação social, via emancipação por meio da Educação.

\section{REFERÊNCIAS}

ANDRIOLA, Wagner Bandeira; SULIANO, Daniele Cirilo. Avaliação dos impactos sociais oriundos da interiorização da Universidade Federal do Ceará (UFC).

Revista Brasileira de Estudos Pedagógicos, Brasília, v. 96, n. 243, p. 282298, maio/ago. 2015. Disponível em: https://www.scielo.br/pdf/rbeped/v96n243/2176-6681-rbeped-96-24300282.pdf. Acesso em: 30 abr. 2020.

BERTH, Joice. O que é empoderamento? Belo Horizonte: Letramento, 2018.

BOTTONI, Andrea; SARDANO, Edélcio de Jesus; COSTA FILHO, Galileu Bonifácio da. Uma breve história da universidade no brasil: de Dom João a Lula e os desafios atuais. In: COLOMBO, Sonia Simões. (Org.). Gestão

Universitária e os caminhos para a excelência. Porto Alegre: Penso, 2013. p. 19-42.

BOURDIEU, Pierre. Questões de sociologia. Rio de Janeiro: Editora Marco Zero Limitada, 1983.

BRASIL. Decreto $n^{\circ} 7.234$, de 19 de julho de 2010. Dispõe sobre o Programa Nacional de Assistência Estudantil - PNAES. Diário Oficial da União, Brasília, DF, 19 de jul. 2010. Disponível em:

http://www.planalto.gov.br/ccivil_03/_ato2007-

2010/2010/decreto/d7234.htm. Acesso em: 30 abr. 2020. 
CAMARGO, Brigido Vizeu; JUSTO, Ana Maria. IRAMUTEQ: um software gratuito para análise de dados textuais. Temas em Psicologia, Ribeirão Preto, v. 21, n. 2, p. 513-518, dez. 2013. Disponível em:

<http://pepsic.bvsalud.org/pdf/tp/v21n2/v21n2a16.pdf>. Acesso em: 30 abr. 2020.

CATÃO, Maria de Fátima Martins. Projeto de vida em construção: na exclusão/inserção social. João Pessoa: UFPB/Editora universitária, 2001.

CORBUCCI, Paulo Roberto et al. (2009). Situação educacional dos jovens brasileiros. In: CASTRO, Jorge Abrahão. de; AQUINO, Luseni Maria Cordeiro de; ANDRADE, Carla Coelho de. (Orgs.). Juventude e políticas sociais no Brasil. Brasília: Ipea, 2009. p. 91-108.

DAMASCENO, Maria Nobre. Trajetórias da juventude: caminhos, encruzilhadas, sonhos e expectativas. In: DAMASCENO, Maria Nobre; MATOS, Kelma Socorro Lopes de; VASCONCELOS, José Gerardo. (Org.). Trajetórias da Juventude. Fortaleza: Gráfica e Editora LCR, 2001. p. 09-24.

EVANGELISTA, Joelma Inês; MACIEL, Carina Elisabeth. Política de cotas na educação superior: lutas e desafios no combate à pobreza e desigualdade de estudantes negros. Revista Inter-Ação, Goiânia, v. 44, n. 1, p. 111-127, jan./abr. 2019. Disponível em:

https://www.revistas.ufg.br/interacao/article/view/55654/33079. Acesso em: 30 abr. 2020.

FERNANDES, Dorgival Gonçalves. Ir-remediável campo de sonhos de futuro: representações sociais da escola entre jovens estudantes de escolas públicas no sertão nordestino. 2003. 298f. Tese (Doutorado em Educação) Centro de Educação e Ciências Humanas, Universidade Federal de São Carlos, São Carlos, 2003.

FREIRE, Paulo. Pedagogia do oprimido. 45a . Ed. Rio de Janeiro: Paz e Terra, 2005.

HONNETH, Axel. Luta por reconhecimento: a gramática moral dos conflitos sociais. São Paulo: Editora 34, 2003.

HURTADO, Daniela Haertel. Projetos de vida e projetos vitais: um estudo sobre projetos de jovens estudantes em condição de vulnerabilidade social da cidade de São Paulo. 2012. 170f. Dissertação (Mestrado em Educação) Faculdade de Educação, Universidade de São Paulo, São Paulo, 2012.

LAHIRE, Bernard. Sucesso escolar nos meios populares: as razões do improvável. São Paulo: Ática, 1997. 
MARTINS, José de Souza. A sociabilidade do homem simples: cotidiano e história na modernidade anômala. 3a. Ed. São Paulo: Contexto, 2011.

MENDONÇA, Ana Waleska Pollo Campos. A universidade no Brasil. Revista Brasileira de Educação, Rio de Janeiro, v. 14, p. 131-150, maio/ago. 2000. Disponível em: https://www.scielo.br/pdf/rbedu/n14/n14a08.pdf. Acesso em: 30 abr. 2020.

MINAYO, Maria Cecília de Souza. O desafio do conhecimento: pesquisa qualitativa em saúde. 11. ed. São Paulo: Hucitec, 2008.

MINAYO, Maria Cecília de Souza. (Org.). Pesquisa social: teoria, método e criatividade. 18a. Ed. Petrópolis: Vozes, 2001.

NIEROTKA, Rosileia Lucia; TREVISOL, Joviles Vitório. Os jovens das camadas populares na universidade pública: acesso e permanência. Revista Katálysis, Florianópolis, v. 19, n. 1, p. 22-32, jan./jun. 2016. Disponível em:

https://www.scielo.br/pdf/rk/v19n1/1414-4980-rk-19-01-00022.pdf. Acesso em: 30 abr. 2020.

OLIVEIRA, Jane Souto de. Barreiras, transgressões e invenções de mercado: a inserção econômica de jovens pobres. In: ENCONTRO NACIONAL DE ESTUDOS POPULACIONAIS, 12., 2000, Caxambu. Anais [...]. Caxambu: ABEP, 2000. p. 1-24. Disponível em:

http://www.abep.org.br/publicacoes/index.php/anais/article/view/1025/989. Acesso em: 30 abr. 2020.

OLIVEIRA, Márcia Gardênia Monteiro de; QUINTANEIRO. Tania. Karl Marx. In: QUINTANEIRO, Tania; OLIVEIRA, Márcia Gardênia Monteiro de; BARBOSA, Maria Ligia de Oliveira. (Org.). Um toque de clássicos: Marx, Durkheim e Weber. 2a. Ed. Minas Gerais: Editora UFMG, 2003. p. 27-65.

ORLANDI, Eni Pulcinelli. Análise de Discurso: princípios \& procedimentos. 8a. Ed. Campinas: Pontes, 2009.

PAIS, José Machado. A construção sociológica da juventude: alguns contributos. Revista Análise Social, Lisboa, v. 25, n. 105-106, p. 139-165, 1990. Disponível em:

http://analisesocial.ics.ul.pt/documentos/1223033657F3sBS8rp1Yj72MI3.pdf. Acesso em: 30 abr. 2020.

PATTO, Maria Helena de Souza. A produção do fracasso escolar: histórias de submissão e rebeldia. 4a. Ed. São Paulo: Intermeios, 2015.

PATTO, Maria Helena de Souza. Estado, ciência e política na Primeira República: a desqualificação dos pobres. Estudos Avançados, São Paulo, v. 13, n. 35, p. 167-198, jan./abr. 1999. Disponível em: 
https://www.scielo.br/pdf/ea/v13n35/v13n35a17.pdf. Acesso em: 30 abr. 2020.

PAULA, Maria de Fátima Costa de. Educação superior e inclusão social na América Latina: um estudo comparado entre Brasil e Argentina. In: PAULA, Maria de Fátima Costa de; LAMARRA, Norberto Fernández. (Orgs.). Reformas e democratização da educação superior no Brasil e na América Latina. Aparecida: Idéias \& Letras, 2011. p. 53-96.

PIOTTO, Débora Cristina. A escola e o sucesso escolar: algumas reflexões à luz de Pierre Bourdieu. Revista Vertentes, São João del-Rei, n. 33, p. 48-60, 2009. Disponível em: https://ufsj.edu.br/portal2-

repositorio/File/vertentes/debora_piotto.pdf. Acesso em: 30 abr. 2020.

PIOTTO, Débora Cristina. As exceções e suas regras: estudantes das camadas populares em uma universidade pública. 2007. 361f. Tese (Doutorado em Psicologia) - Instituto de Psicologia, Universidade de São Paulo, São Paulo, 2007.

PIOTTO, Débora Cristina. Universitários de camadas populares em cursos de alta seletividade: aspectos subjetivos. Revista Brasileira de Orientação Profissional, Porto Alegre, v. 11, n. 2, p. 229-242, jul./dez. 2010. Disponível em: http://pepsic.bvsalud.org/pdf/rbop/v11n2/v11n2a08.pdf. Acesso em: 30 abr. 2020.

PIOTTO, Débora Cristina; ALVES, Renata Oliveira. O ingresso de estudantes das camadas populares em uma universidade pública: desviando do ocaso quase por acaso. Revista de Educação PUC-Campinas, Campinas, v. 21, n. 2, p. 139-147, maio/ago. 2016. Disponível em: https://seer.sis.puccampinas.edu.br/seer/index.php/reveducacao/article/view/2896/2284. Acesso em: 30 abr. 2020.

PRIORE, Mary Del; PINSKY, Carla Silvia Beozzo Bassanezi. História das mulheres no Brasil. 10. ed. São Paulo: Contexto, 2012.

RÊGO, Ernny Coêlho; BENEVIDES, Marinina Gruska. A Assistência Estudantil e a redução das desigualdades sociais no contexto de fragilização das políticas sociais. Revista Inter-Ação, Goiânia, v. 44, n. 1, p. 151-163, jan./abr. 2019. Disponível em: https://www.revistas.ufg.br/interacao/article/view/55626/33086. Acesso em: 30 abr. 2020.

SANTOS, Laís Santana. A juventude de origem popular em busca do ensino superior público: entre sonhos, dificuldades e desigualdades. Scientia Plena, São Cristóvão, v. 5, n. 11, p. 1-11, nov. 2009. Disponível em: https://scientiaplena.org.br/sp/article/view/753/406. Acesso em: 30 abr. 2020. 
SAWAIA, Bader. As artimanhas da exclusão: análise psicossocial e ética da desigualdade social. 10. ed. Petrópolis: Vozes Limitada, 2017.

SCHWARTZMAN, Simon. Perspectivas para a educação superior no Brasil. In: NEGRI, João Alberto de; ARAÚJO, Bruno César; BACELETTE, Ricardo. (Eds.). Desafios da nação: artigos de apoio. Brasília: Ipea, 2018. p. 333-353.

SILVA, Ivone Maria Mendes; LEME, Maria Isabel Silva. Projetos de vida e educação: narrativas de jovens das camadas populares sobre suas experiências. Revista Inter-Ação, Goiânia, v. 44, n. 1, p. 77-92, jan./abr. 2019. Disponível em: https://www.revistas.ufg.br/interacao/article/view/55686/33073. Acesso em: 30 abr. 2020.

SOUZA, Jessé. A ralé brasileira: quem é e como vive. Belo Horizonte: Editora UFMG, 2009.

SOUZA, Jessé. (Não) Reconhecimento e subcidadania, ou o que é "ser gente"? Lua Nova: Revista de Cultura e Política, São Paulo, n. 59, p. 51-73, 2003. Disponível em: https://www.scielo.br/pdf/In/n59/a03n59.pdf. Acesso em: 30 abr. 2020.

TEIXEIRA, Elaine Juncken. Juventude pobre, participação e redes de sociabilidade na construção do projeto de vida. 2005. 139f. Dissertação (Mestrado em Psicologia) - Instituto de Psicologia, Universidade Federal do Rio de Janeiro, Rio de Janeiro, 2005.

ZAGO, Nadir. Do acesso à permanência no ensino superior: percursos de estudantes universitários de camadas populares. Revista Brasileira de Educação, Rio de Janeiro, v. 11, n. 32, p. 226-237, maio/ago. 2006. Disponível em: https://www.scielo.br/pdf/rbedu/v11n32/a03v11n32.pdf. Acesso em: 30 abr. 2020.

ZAGO, Nadir; PAIXÃO, Lea Pinheiro; PEREIRA, Thiago Ingrassia. Acesso e permanência no ensino superior: problematizando a evasão em uma nova universidade federal. Educação em foco, Belo Horizonte, v. 19, n. 27, p. 145169, jan./abr. 2016. Disponível em:

http://revista.uemg.br/index.php/educacaoemfoco/article/view/1334/953. Acesso em: 30 abr. 2020. 